\title{
O MUSEU DE ARTES VISUAIS DA UNICAMP. SUA COLEÇÃO E SEUS OBJETIVOS
}

\author{
Maria de Fátima Morethy Couto ${ }^{*}$
}

\section{RESUMO:}

A Universidade Estadual de Campinas é uma das maiores universidades públicas do Brasil. Conta hoje com mais de 50 cursos de graduação, nas mais diferentes áreas do saber (ciências exatas, tecnológicas, biomédicas, humanidades e artes) e três museus (Zoologia, Exploratório de Ciências e Artes Visuais).A qualidade da formação oferecida pela Unicamp é favorecida pela relação que historicamente mantém entre ensino, pesquisa $\mathrm{e}$ extensão. O Museu de Artes Visuais da Unicamp,ainda em fase de implantação, tem como missão possibilitar a difusão da educação, pesquisa e do conhecimento em artes visuais e promover uma reflexão aprofundada sobre a arte na contemporaneidade. Para tanto, tirará proveito da sólida estrutura institucional da Unicamp. Meu artigo tem por objetivo apresentar o acervo do museu e discutir as questões específicas que a diversidade de seu acervo nos trazem, em especial em termos de definição dos eixos conceituais que presidirão sua expansão.

\section{PALAVRAS-CHAVES:}

Universidade Estadual de Campinas, museus universitários, Museu de Artes Visuais da Unicamp

\begin{abstract}
:
The University of Campinas is one of the largest and most important public universities in Brazil. It has nowadays more than 50 undergraduate programs in different areas of knowledge (sciences, technology, biomedical, humanities and arts) and three museums (Zoology, Sciences and Visual Arts). The quality of the education provided by Unicamp is favored by the relationship that the university historically maintains between teaching, research and extension.The Museum ofVisualArts/ UNICAMP,still under implementation, has the mission of enabling the dissemination of education, research and knowledge in visual arts. It aims to be a forum of reflection on art in contemporary times. For that, it will certainly benefit from the solid institutional structure of Unicamp. My article aims to present the collection of the museum and discuss the issues that the diversity of its collection bring to us, especially in terms of the definition of the conceptual axes that will govern its expansion.
\end{abstract}

\section{KEY-WORDS:}

University of Campinas, university museums, Museum of Visual Arts/ Unicamp

I * Professora Livre-Docente do Departamento de Artes Plásticas e do Programa de Pós-graduação em Artes Visuais da Unicamp. Diretora do Museu de Artes Visuais da Unicamp desde sua fundação. 
O Museu de Artes Visuais da UNICAMP (MAV/UNICAMP) foi criado oficialmente em janeiro de 2012 e conta hoje com um acervo de cerca de 1.000 obras, a maioria de caráter bidimensional, que foram adquiridas ou incorporadas ao acervo ao longo dos mais de 20 anos de atuação da galeria de artes do Instituto de Artes/Unicamp, fundada em 1984, e foram doadas, pela Direção do Instituto de Artes, em agosto de 2009, à Reitoria da Universidade com o objetivo de possibilitar a criação do novo museu e a construção de uma sede própria. $^{2}$

De modo similar à história de diversos outros museus universitários, a coleção do MAV tem origem em ações pontuais de um grupo específico de pesquisadores, docentes do Instituto de Artes, que criaram uma galeria com o objetivo de promover as artes visuais e incentivar a difusão e compreensão da arte contemporânea junto à comunidade universitária e ao público externo em geral. ${ }^{3}$ Esta mesma galeria funciona atualmente no andar térreo da Biblioteca Central da UNICAMP e continua a organizar exposições e atividades diversas, ligadas ao ensino, à pesquisa e à extensão.Várias mostras relacionadas à defesa de pesquisas de mestrado e de doutorado empreendidas por alunos da universidade são ali realizadas, além de debates e palestras de caráter diversos.

O MAV possui obras de importantes artistas plásticos brasileiros atuantes nos séculos $\mathrm{XX}$ e XXI, como Geraldo de Barros, Marcelo Grassmann, Hermelindo Fiaminghi, Hércules Barsotti, Antônio Henrique Amaral e Renina Katz. Destacam-se, deste conjunto, em razão de seu número, as 55 obras da série Jogos de Dados, do artista paulistano Geraldo de Barros, um dos fundadores do grupo concretista Ruptura, e as quase 300 obras do pintor de origem polonesa Anatol Wladislaw, também integrante do grupo concreto no início dos anos 1950, doadas pela viúva do artista. Estes dois artistas, juntamente com Hermelindo Fiaminghi e Hércules Barsotti participaram ativamente da defesa de uma arte abstrata de cunho racional no Brasil do pós-guerra, com trabalhos que romperam com o caráter representativo da arte e adotaram o elemento geométrico como valor autônomo. Tratava-se, naquela ocasião, de assumir uma postura universalizante no campo das artes visuais, que fizesse frente ao discurso de viés nacionalista que ainda predominava em nosso meio artístico. Visava-se, ainda, criticar a exaltação do caráter subjetivo do fazer artístico, por meio de obras em que prevalecem o cálculo, o método, e nas quais não há lugar para pinceladas expressivas ou constrastes cromáticos acentuados.

Em função de sua história, o museu também reúne um número significativo de desenhos e pinturas de artistas plásticos que atuaram predominantemente na cidade de Campinas e região, e cuja ação foi determinante para o fim do predomínio das tradições acadêmicas na cidade, no final dos anos 1950. Estes trabalhos formaram o núcleo inicial do acervo da galeria e se constituem, numericamente, em parte expressiva de nossa coleção. É importante ressaltar que muitos dos artistas campineiros de "vanguarda" atuantes nos anos 1950 sofreram forte influência do trabalho dos artistas concretos de São Paulo, como Franco Sacchi e Raul Porto. ${ }^{4}$

2 Neste cálculo não estão incluídas as obras de Arte Postal, das quais falarei mais adiante.

3 A galeria foi inaugurada em 1984 em uma sala do antigo prédio do Restaurante Universitário, e sua criação ocorreu em paralelo à própria fundação do Instituto de Artes da Unicamp, por iniciativa de um grupo de professores do recém-fundado Departamento de Artes Plásticas. As primeiras obras foram doadas à galeria a partir de um projeto elaborado pelo professor Bernardo Caro, o qual organizou uma exposição coletiva em centro cultural de Campinas, intitulada Arcervo Unicamp 1984, e solicitou a doação de trabalhos para os artistas atuantes na região.

4 Notas publicadas nos jornais de Campinas, no final da década de 1950, comprovam a presença dos artistas e poetas concretos de São Paulo na cidade, promovendo exposições, palestras e cursos e demons- 


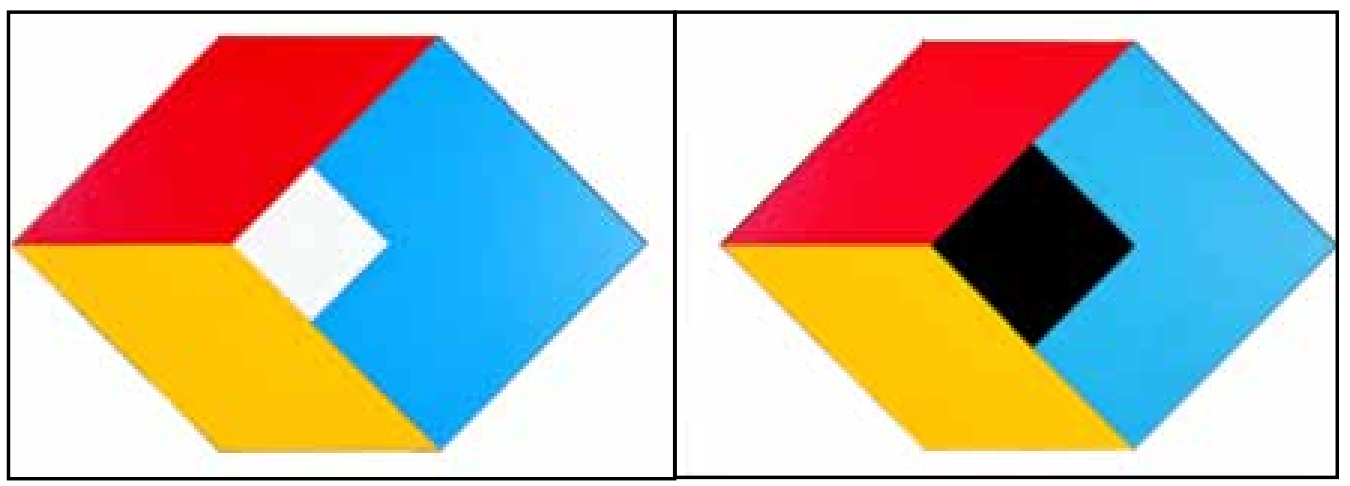

Figs. I e 2. Geraldo de Barros. Série Jogos de Dados. Fórmica sobre Madeira, 38 x 58 cm, 1983. Coleção MAV/Unicamp

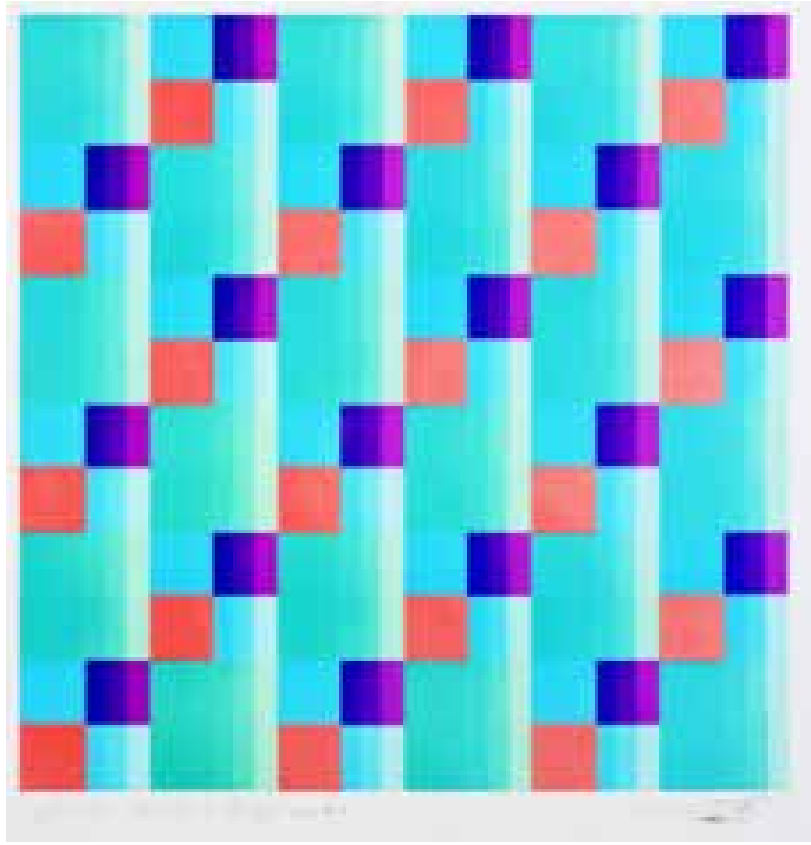

Fig. 3. Hermelindo Fiaminghi.

Retícula Cor/luz - Permuta.

Serigrafia sobre papel, $64 \times 64 \mathrm{~cm}$, 1974. Coleção MAV/Unicamp

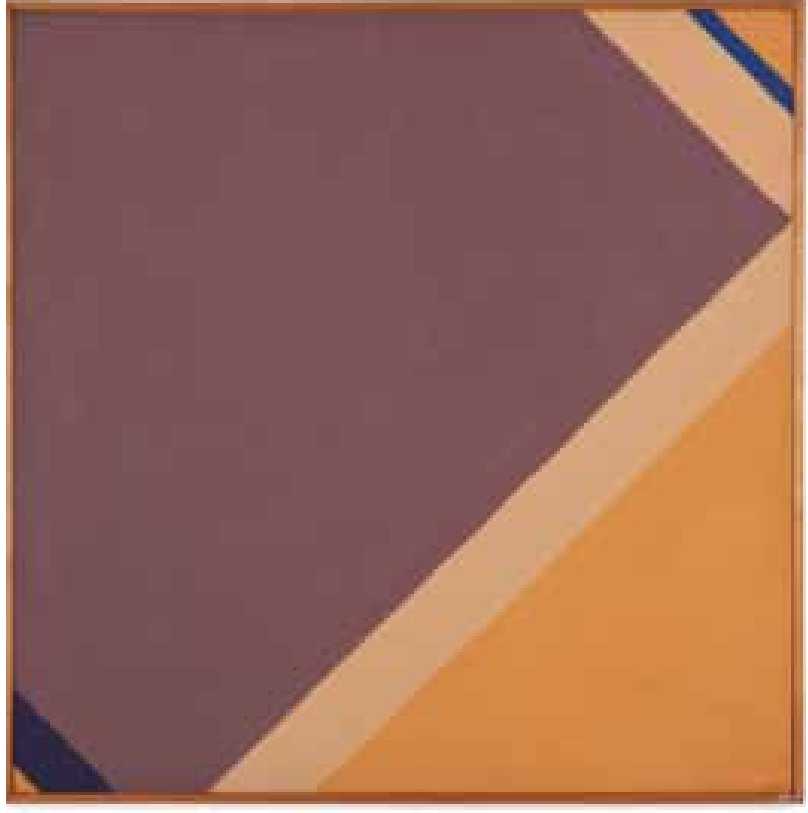

Fig. 4. Raul Porto, Sem titulo. Acrílica sobre tela, $77 \times 77 \mathrm{~cm}$, 1979. Coleção MAV/Unicamp

tram que o grupo concretista manifestou recorrentemente seu apoio aos artistas de Campinas. 
Contudo, embora seja possível afirmar que houve um produtivo entrosamento entre os artistas de Campinas e o grupo concreto paulista, faz-se necessário assinalar que os concretistas de São Paulo possuíam um ideal coletivo, compartilhavam dos mesmos princípios e visavam objetivos similares; já os artistas de Campinas desenvolviam trabalhos com características bastante diversas, sem princípios rígidos que o norteassem.

Mário Bueno e Thomaz Perina, por exemplo, dois artistas de grande representatividade na região e também no MAV, compraziam-se em representar paisagens dos subúrbios de Campinas, casarios em meio a elementos naturais, trens que percorrem a malha ferroviária. Exímios pintores, amantes do ofício, exploravam questões formais, plásticas, sem abdicar por completo das referências figurativas. Por mais que seus trabalhos do final dos anos 1950 flertem com a abstração, eles jamais se interessaram por uma abstração de cunho racional, mantendo certa espontaneidade e lirismo em suas composições, servindo-se recorrentemente de tons rebaixados sutilmente contrastados. O gesto autoral é importante, o pincel, usado com elegância, expressa a sensibilidade de seu autor.

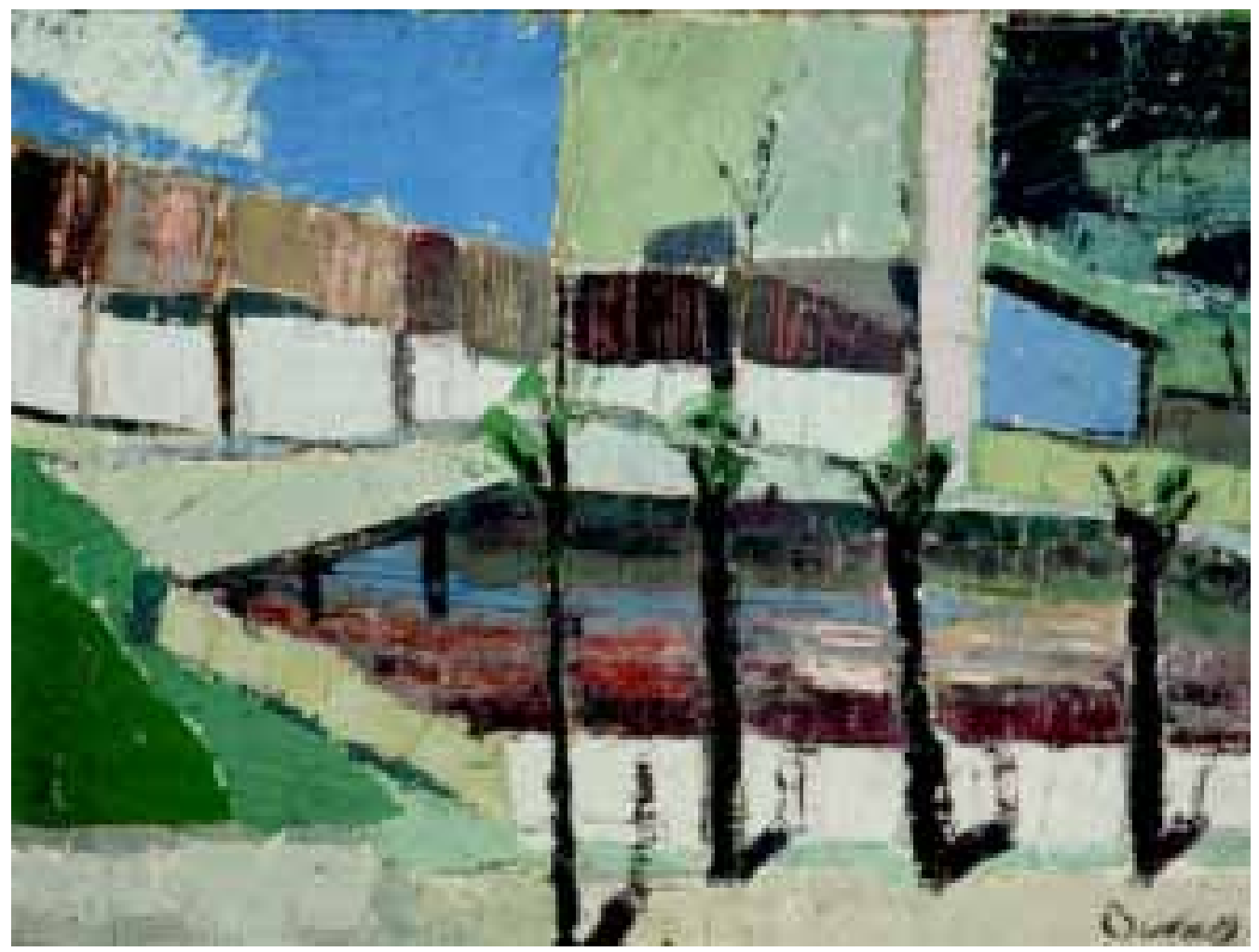

Fig. 5. Mário Bueno, Pintura V. Óleo sobre tela, 85 × 100 cm, 1964. Coleção MAV/Unicamp

Embora jamais tenha tido uma política efetiva de aquisições, algumas ações puderam ser realizadas pelo conselho deliberativo da galeria, em diferentes momentos de sua história, com o objetivo de ampliação do acervo. Ressalte-se que o fato de ser uma galeria, e não um museu, dificultou o estabelecimento de uma política de aquisições em termos institucionais, uma vez que a meta maior da galeria era a de promover eventos ligados às artes visuais e estabelecer intercâmbios culturais. Estas ações esporádicas resultaram basicamente na compra de obras de artistas locais, o que aumentou ainda mais esta parcela do acervo. Em 2002, por exemplo, foi adquirido um total de 250 obras do artista campineiro Mário Bueno (1919-200I), incluindo-se aí 104 estudos, 21 pinturas a óleo e várias séries em papel, de diferentes fases de sua carreira 
(xilogravuras, desenhos a nanquim e acrílica sobre papel). Nesta ocasião, a família de Bueno doou para a galeria diversos documentos pessoais por ele conservados, tais como recortes de jornal e revistas sobre seu trabalho e sobre o movimento artístico em geral, catálogos de exposição, escritos inéditos, fotografias e livros. Outra compra marcante foi a da coleção Arruda, efetuada em 2007, composta por um total de 46 obras, a maioria, novamente, de artistas campineiros do chamado grupo Vanguarda. ${ }^{5}$ Nestes dois casos, creio que 0 fato de serem trabalhos de artistas de destaque na região favoreceu o processo de aquisição, uma vez que a Unicamp, por sua localização geográfica, tem relação especial com a cidade de Campinas e seu entorno.

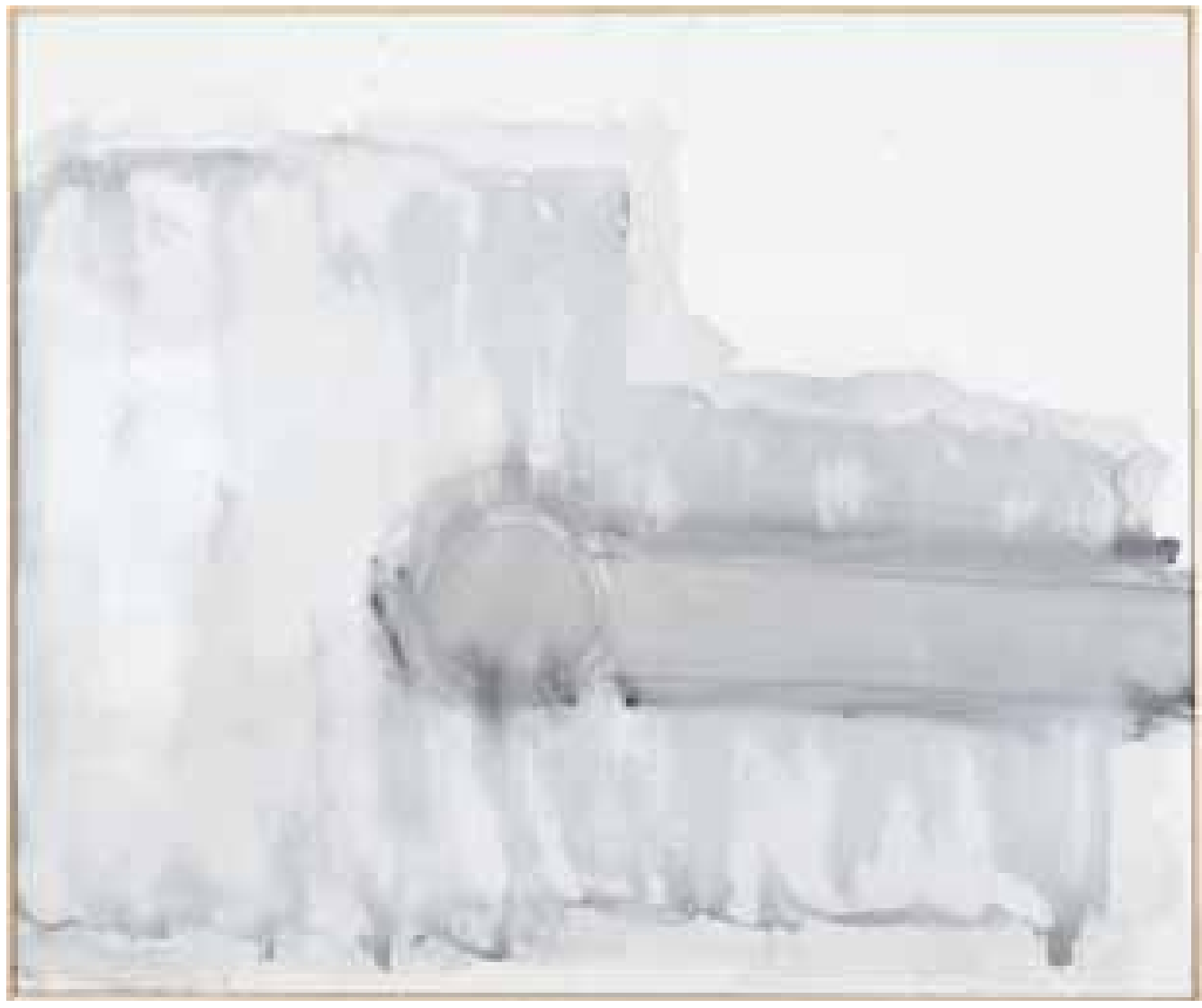

Fig. 6. Thomaz Perina, Paisagem I. Acrílica sobre papel, 48 × 64 cm, 1998. Coleção MAV/Unicamp

Além das obras de professores do Instituto de Artes e de jovens artistas que expuseram na galeria e ali deixaram alguns de seus trabalhos, o MAV possui ainda um acervo significativo de arte postal, que se encontra em fase de catalogação e que foi constituído a partir do Núcleo de Arte Postal da Unicamp, ativo nos anos 1980 por iniciativa dos artistas Gilbertto Prado e Lúcia Fonseca, entre outros. ${ }^{6}$ Interessados em estimular a criação em rede, o Núcleo de Arte

5 Fundado em Campinas em 1958, com o objetivo de "conquistar espaço, agenda e mercado para um grupo jovem, que indubitavelmente já havia iniciado o movimento de descolamento da cena acadêmica", o Grupo Vanguarda contou com a participação de Thomaz Perina, Raul Porto, Mário Bueno, Franco Sacchi, Maria Helena Motta Paes, Edoardo Belgrado, entre outros.

$6 \mathrm{~A}$ arte postal caracteriza-se pela vontade de expandir o conceito tradicional de arte e de criticar a noção de obra de arte enquanto mercadoria, objeto vendável, por meio do estabelecimento de uma rede de artistas que se servem de suportes banais, quotidianos, que são enviados pelo correio e expostos em diferentes lugares do mundo. Trata-se de um desejo de promover a circulação de trabalhos e de informação. O que importa, para os artistas e críticos envolvidos na promoção da arte postal, não é mais o objeto em si nem sua qualidade estética mas sim a ação, a intenção que preside o gesto do artista, bem como a 
Postal enviava convocações e organizava mostras na galeria com o material que recebiam de artistas de todo o mundo. Welcomet Mr. Halley (I 985) e A Terra e Seus Terráqueos (1988) foram alguns dos eventos promovidos neste contexto. Trabalhos de diversas mídias - desenho, fotografia, colagem, vídeo, etc. -, de artistas como Clement Padin, León Ferrari, Diana Domingues, Ricardo Basbaum e Paulo Brusky estão hoje no acervo do MAV devido a essas ações específicas.

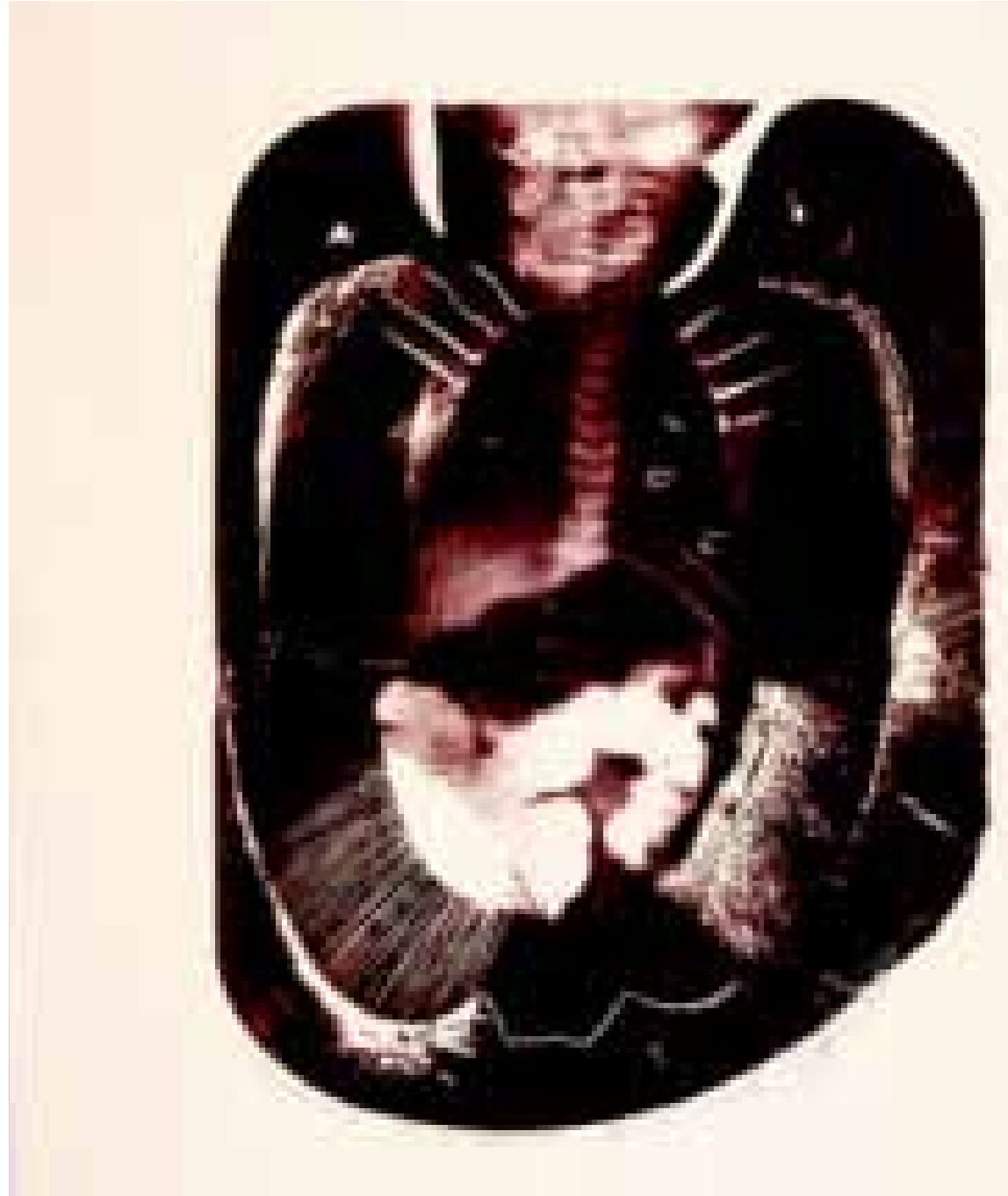

Fig. 7. Paulo Bruscky e Daniel Santiago, Sem título. Heliografia sobre papel, 54 x 47,5 cm, 1990 . Coleção MAV/Unicamp

Trata-se, portanto, de um acervo diversificado, que foi constituído a partir de iniciativas isoladas e sem intenções precisas, mas que tem valor incontestável. Embora ele não contemple amplamente a pluralidade da arte moderna e contemporânea brasileira, nem tampouco possua um conjunto significativo de obras de artistas internacionais consagrados, como é o caso, por exemplo, do Museu de Arte Contemporânea da USP, que teve sua origem na doação de uma coleção privada de grande porte, ele certamente terá lugar de destaque no cenário regional e mesmo nacional. Campinas, como sabemos, é uma cidade que está carente de equipamentos e de atividades culturais.

reflexão que este trabalho, banal e perecível, provoca sobre o sistema de arte no qual ele se insere. Ela tem caráter subversivo, contestador, e quer se manter à margem das instâncias de legitimação artísticas, sem porém renegá-las por completo. 


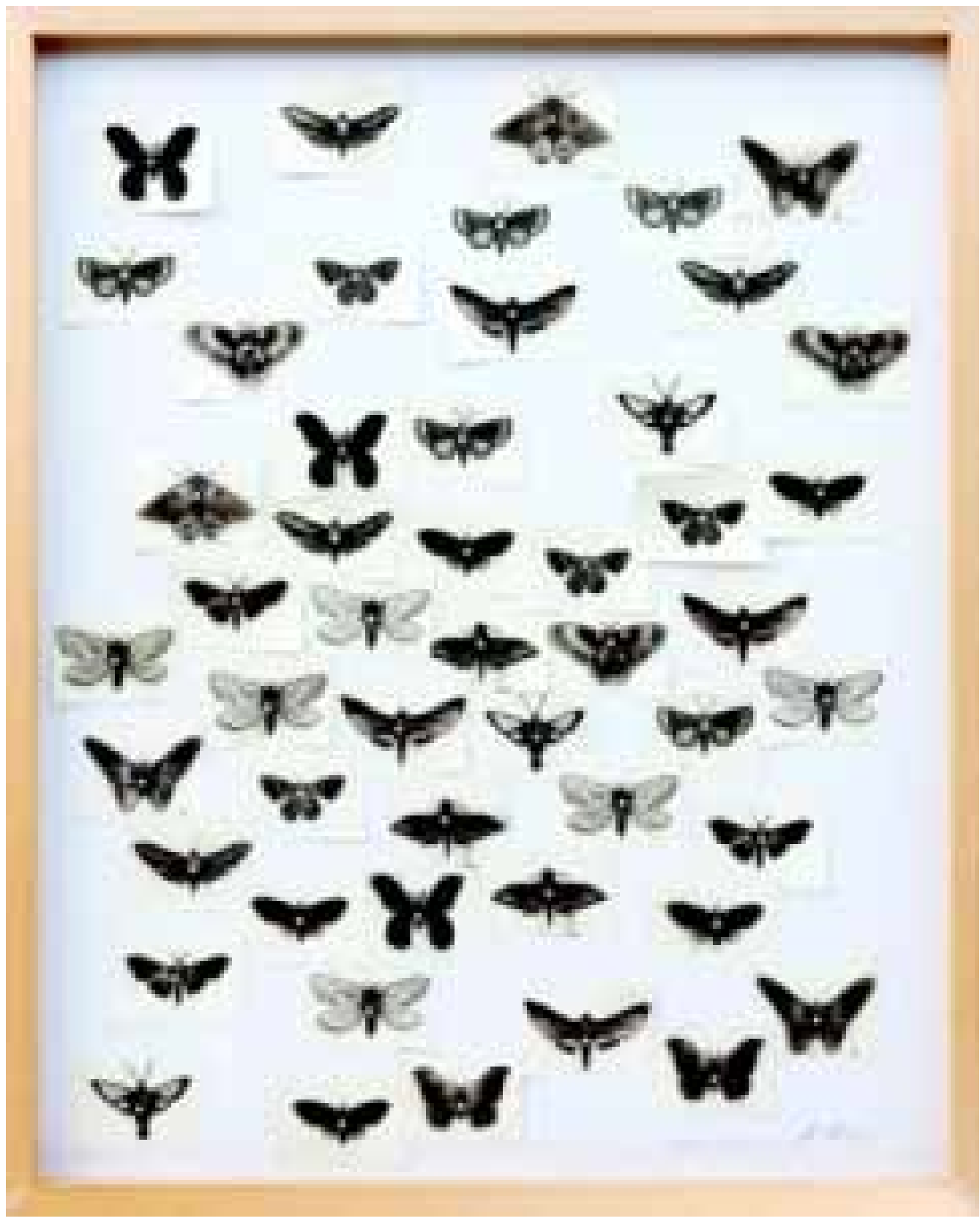

Fig. 8. Marcelo Moscheta, Insectae universalis. Calcografia sobre papel e alfinetes sobre fundo de madeira, 200 x 180 cm, 2003-2006. Coleção MAV/Unicamp

Nosso maior e primeiro desafio, nesse momento, tem sido o de definir os principais eixos do novo museu. ${ }^{7}$ Dentro desse espírito, promovemos uma série de eventos de caráter diverso a fim de discutir os diferentes aspectos, conceituais e práticos, concernentes à implantação, na Unicamp, de uma instituição museológica voltada às artes visuais, entre eles os encontros Museus de arte na atualidade: propósitos e proposições (abril de 20ll) e Coleções e Museus de Arte (dezembro de 20I I), o ciclo de palestras Museus e arte: relações entre o artista, a obra e seu público (setembro/outubro de 20I2), o seminário internacional Eros e Educação (maio de 2013), o Fórum permanente Museu e escola: atravessando fronteiras (junho de 2013) e o II Seminário Studium: coleções fo-

7 O MAV conta com uma Diretoria, composta por mim e pela professora Ana Angélica Medeiros Albano, e uma Comissão Executiva, que tem como integrantes os professores Antônio Carlos Rodrigues (Tuneu), Lúcia Reilly, Marco Antônio Alves do Valle e Sylvia Furegatti. 
tográficas (novembro de 2013). Estes eventos contaram com a participação de profissionais de diferentes áreas, brasileiros e estrangeiros, e nos auxiliaram a construir um público interessado nas ações culturais e educativas de um museu universitário, público este que não se restringe à comunidade da Unicamp.

Sendo o MAV um museu universitário e que se encontra portanto inserido nas "lógicas e práticas do campo científico" e é influenciado "pelas práticas de pesquisadores, professores e administradores de tal campo", como bem apontou Emanuela Sousa Ribeiro em artigo publicado em número anterior desta revista (RIBEIRO, 20I3), procuramos privilegiar, em nosso regimento, seu compromisso com a promoção e difusão da educação, pesquisa e do conhecimento em artes visuais.

O MAV tem como missão a exposição, conservação, proteção, valorização e ampliação de seu acervo museológico, arquivístico e bibliográfico. Seus principais objetivos são: Constituir acervo tanto artístico quanto documental; Promover o intercâmbio artístico, intelectual e científico com instituições afins do Brasil e do exterior; Propiciar condições para o desenvolvimento de atividades diversas de criação, ensino, pesquisa e extensão, incentivando em especial projetos de caráter contemporâneo; Divulgar e promover a arte e, em particular, as artes visuais; Ser um espaço de reflexão sobre a arte na contemporaneidade;Assegurar o convívio inclusivo em suas dependências e garantir condições de acessibilidade às suas atividades;Assegurar a diversidade cultural em sua programação.

Para cumprir estes objetivos o MAV se propõe a: Realizar pesquisas próprias ou em convênios com outras instituições; Organizar, produzir e realizar eventos artístico-culturais relacionados à missão do Museu de Artes Visuais; Colaborar na criação e funcionamento de cursos de graduação, pós-graduação, especialização, extensão e treinamento, nas áreas de sua competência; Prestar serviços nas áreas de arte e educação estética por meio de convênios, contratos de serviço ou programas de colaboração; Ser um espaço de reflexão, educação e difusão da arte por meio da realização de exposições permanentes, exposições temporárias, exposições itinerantes, cursos, palestras, debates e outras atividades culturais; Assegurar a devida conservação de seu acervo artístico e documental, tomando todas as medidas de segurança necessárias aos bens culturais colocados sob a guarda da Unicamp; Manter serviço de informação on-line sobre seu acervo e as diversas atividades promovidas pelo Museu (www.mav.unicamp.br).

O MAV será locado no campus Barão Geraldo da Unicamp, na esquina das ruas Bertrand Russell com Claudio Abramo. Sua primeira etapa de construção teve início em fevereiro de 20l4. O programa arquitetônico, que foi concebido sob a supervisão do professor Leandro Medrano, que hoje leciona na FAU/USP, está organizado em $3.232 \mathrm{~m} 2$ de área coberta e $1.100 \mathrm{~m} 2$ de área externa. Seu projeto também reserva $5.000 \mathrm{~m} 2$ para futura expansão.

As soluções adotadas seguem padrões internacionais recomendados aos museus de arte e deverão, além de possibilitar a exposição, manutenção e proteção do acervo do MAV, proporcionar um local singular de convívio, que intensifique as possibilidades da arte e da cultura no campus.

\section{Referências}

ALMEIDA, Adriana Mortara. Museus e coleções universitários: por que museus de arte na Universidade de São Paulo. Tese (Doutorado em Ciências da Informação e Documentação): USP, $200 \mathrm{I}$.

AMARAL,Aracy (org.). Perfil de um Acervo: Museu de Arte Contemporânea da Universidade de São Paulo. São Paulo: MAC USP/TECHINT, 1988. 
AMARAL,Aracy.Textos do Trópico de Capricórnio, (Vol. 2: Circuitos de Arte na América Latina e no Brasil). São Paulo: Ed. 34, 2006.

COSTA, Helouise. "Da fotografia como arte à arte como fotografia: a experiência do Museu de Arte Contemporânea da USP na década de 1970". In:Anais do Museu Paulista, v. 16, n 2, jul.-dez. 2008.

FREIRE, Cristina. Poéticas do processo: Arte conceitual no museu. São Paulo: Iluminuras, 1999.

LOURENÇO, Maria Cecília França. Museus acolhem o moderno. São Paulo: EDUSP, 1999.

MATTOS, Claudia Valladão e ELUF, Lygia (orgs). Coleções de arte da Unicamp. Campinas, Ed. Unicamp, 2012.

RIBEIRO, Emanuela Sousa. "Museus em Universidades Públicas: entre o campo científico, o ensino, a pesquisa e a extensão”. In: Museologia \& Interdisciplinaridade. Brasília, UnB, n 4, p. 88-I0I, 2013 